\title{
Turismo rural na agricultura familiar: análise dos subsídios repassados aos agricultores pelas entidades ligadas à área rural em Santa Cruz do Sul ${ }^{1}$
}

\author{
Rural tourism in family agriculture: analysis of grants passed on to \\ farmers by entities connected to rural area in Santa Cruz do Sul
}

Gabriela Umann Goerck

Universidade de Santa Cruz do Sul - UNISC - Santa Cruz do Sul - Rio Grande do Sul - Brasil

\begin{abstract}
$\longrightarrow$
Resumo: O turismo rural é uma atividade que vem se desenvolvendo, principalmente dentro das propriedades de agricultores familiares. No entanto, muitos deles não têm conhecimento dos subsídios que entidades ligadas à área rural podem oferecer para a implantação do turismo nestas propriedades. Assim o trabalho objetivou identificar quais os subsídios que estas entidades repassam para os agricultores que pretendem trabalhar o turismo em suas propriedades, bem como verificar quais as políticas públicas que podem ser utilizadas pelos agricultores na implantação e manutenção do turismo rural. Esta análise foi feita a partir de um estudo de caso, realizado no Sítio 7 Águas, empreendimento de turismo rural de Santa Cruz do Sul - RS confrontando com o que as entidades Senar e Emater/Ascar instaladas na região do Vale do Rio Pardo, onde o município se insere, dizem repassar aos agricultores familiares que pretendem trabalhar o turismo rural em suas propriedades.
\end{abstract}

Palavras-chave: Turismo rural. Agricultura familiar. Políticas públicas.

\begin{abstract}
Rural tourism is an activity that has been developing, mainly within the properties of family farmers. However, many of them are not aware of the subsidies that entities related to the rural area can offer for the implementation of tourism in these properties. Thus, the objective of this work was to identify the subsidies that these entities pass on to farmers who intend to work tourism on their properties, as well as to verify which public policies can be used by farmers in the implementation and maintenance of rural tourism. This analysis was made from a case study, carried out at Sítio 7 Águas, a rural tourism project in Santa Cruz do Sul - RS, confronting what the Senar and Emater/Ascar entities installed in the region of the Rio Pardo Valley, where The municipality is inserted, they say to the family farmers who intend to work rural tourism on their properties.
\end{abstract}

Keywords: Rural tourism; family agriculture; public policy.

\footnotetext{
${ }^{1}$ Trabalho apresentado ao Curso de Turismo da Universidade de Santa Cruz do Sul - UNISC, dez/2014 para a obtenção do título de Bacharel em Turismo. Primeira versão do artigo apresentada no 3ํㅗ Seminário de Desenvolvimento Regional - SEDRES - set/2016.
} 



\section{Introdução}

As transformações ocorridas no espaço rural brasileiro, principalmente no que se refere às relações e formas de trabalho, têm permitido aos agricultores familiares a possibilidade do aumento da renda familiar. Essas transformações vêm chamando atenção de várias áreas e setores, principalmente a acadêmica, que vem analisando essas novas relações (PROGRAMA NACIONAL DE TURISMO RURAL NA AGRICULTURA FAMILIAR, 2004).

Essas transformações apontam para a abertura de um novo processo produtivo rural, que abre espaço para a consolidação de atividades como o turismo, que vem surgindo também na agricultura familiar.

Além disso, é possível perceber que o meio rural vem sendo cada vez mais requisitado como ambiente de lazer, principalmente por pessoas que vivem nos centros urbanos e que procuram por silêncio, ar puro, descanso e belas paisagens. Nesse sentido, surge o segmento de turismo rural que, no Brasil, é uma atividade que se desenvolve cada vez mais e que traz benefícios ao produtor rural, que pode agregar uma nova fonte de renda à sua produção, e ao turista, que cansado do stress do dia a dia, busca a área rural para descanso, lazer e diversão.

O turismo rural vem se desenvolvendo em grande parte, a partir da agricultura familiar, e, normalmente, é produto da iniciativa de agricultores que procuram novas formas de geração de renda. Para tanto, algumas entidades tem apoiado estas iniciativas, seja por meio da extensão rural e ou da assistência técnica.

Conforme o Programa Nacional de Turismo Rural na Agricultura Familiar (2004), foi no início da década de 1990, que surgiram os primeiros projetos de assistência técnica rural, incluindo o turismo como força de trabalho na agricultura familiar. No entanto, ainda hoje, muitos agricultores não têm consciência de quais os subsídios que as entidades podem oferecer e muitas vezes deixam de pensar a atividade turística devido a esta falta de conhecimento.
Diante disso, o trabalho tem por objetivo identificar quais os subsídios que as entidades relacionadas à área rural repassam para os agricultores familiares que pretendem implantar o turismo rural como forma de diversificação de renda, assim como verificar quais as políticas públicas que podem ser utilizadas pelos mesmos na implantação e manutenção do turismo rural na propriedade.

Para isso, foi realizado um estudo de caso no empreendimento de turismo rural Sítio 7 Águas, localizado no município de Santa Cruz do Sul - RS, onde foram analisados quais os subsídios oferecidos ao mesmo, confrontando com o que os gestores das entidades ligadas à área rural da região do Vale do Rio Pardo - a qual o município está inserido - dizem repassar aos agricultores familiares que pretendem trabalhar o turismo rural em suas propriedades.

\section{Turismo rural}

O turismo rural, apesar de ser um fenômeno antigo, só recentemente vem chamando a atenção dos estudiosos, isso porque é um setor com grande capacidade de geração de renda e emprego.

Conforme o Panorama Empresarial de Turismo Rural realizado pelo Instituto de Desenvolvimento do Turismo Rural (IDESTUR) em 2010, estima-se, com base em dados da Organização Mundial do Turismo que pelo menos $3 \%$ de todos os turistas do mundo orientam suas viagens para este segmento. A mesma fonte indica que o turismo rural apresenta um crescimento anual de aproximadamente $6 \%$, o que o caracteriza como uma nova tendência global.

Ainda conforme o Panorama, de modo geral, desde os anos 50 as atividades turísticas rurais são consideradas estratégias de desenvolvimento local e regional em muitos países ao norte e centro da Europa, tendo início no Brasil por volta dos anos 80 e sendo atualmente o segmento que mais cresce, cerca de $30 \%$ ao ano.

Conforme Ruschmann (1997), a deterioração dos grandes centros urbanos faz com que, cada vez mais, a população urbana procure por regiões com belezas naturais, já que o dia a dia na cidade muitas 
vezes impossibilita o contato com a natureza e com a tranquilidade encontrada no meio rural.

Contudo, o turismo no meio rural é uma modalidade relativamente nova no Brasil, se comparado com outros modelos como o de sol e praia. De acordo com Almeida e Riedl (2000), não existe uma data específica para o início desta atividade no país, porém sabe-se que as primeiras iniciativas ocorreram no município de Lages, Santa Catarina, em 1986. Lá uma fazenda propôs acolher visitantes para passar um dia no campo, sendo- Ihes oferecido pernoite e participação nas lidas do campo.

Segundo Moletta (2000), o turismo rural é uma atividade de lazer que o homem urbano procura junto às propriedades rurais, buscando o contato com a natureza e o resgate de suas origens culturais, bem como a valorização da cultura local. Para o homem do campo, significa uma forma de aumentar a sua renda mensal, valorizando sua propriedade e ao mesmo tempo seu estilo de vida.

De acordo com o Ministério do Turismo podese entender o turismo rural como "o conjunto das atividades turísticas desenvolvidas no meio rural, comprometidas com a produção agropecuária, agregando valor a produtos e serviços, resgatando e promovendo o patrimônio cultural e natural da comunidade".

Zimmermann citado por Santos (2005), observa que o turismo rural tem como princípio satisfazer as necessidades de todos os envolvidos, sejam proprietários ou visitantes, promovendo uma alternativa de desenvolvimento para as comunidades rurais, como uma fonte de renda e diminuição do êxodo rural e explica que para atender as expectativas dos visitantes, os gestores das propriedades de turismo rural precisam seguir alguns princípios básicos que são: autenticidade, harmonia ambiental, preservação das raízes, divulgação dos costumes e atendimento familiar.

A característica transdisciplinar e multissetorial do turismo permite a valorização dos aspectos naturais, da cultura e da atividade produtiva das comunidades familiares, assim como estimula a recuperação e conservação da economia do território
(PROGRAMA NACIONAL DE TURISMO RURAL NA AGRICULTURA FAMILIAR, 2004).

Como visto, cada vez mais pessoas procuram atividades relacionadas ao turismo rural. Nesse sentido, Moletta (2000) explica que o visitante que busca este tipo de segmento, normalmente é urbano e pode ser dividido em dois grupos: estudantil e familiar.

O estudantil é aquele organizado pelas escolas e universidades com o propósito de vivenciar uma experiência no campo; estudar, na prática, o que se aprende em sala de aula; conhecer as relações entre o homem do campo e o homem urbano ou conhecer técnicas agropastoris.

Já o familiar é aquele onde casais, famílias ou pequenos grupos de amigos se deslocam para áreas rurais por motivos como: necessidade de mudança de ambiente para recuperar energias; contato com a natureza, longe do barulho e da poluição; busca por um lugar não massificado e autêntico; busca por alimentos mais saudáveis, ditos como naturais; convivência com pessoas que possuem estilo de vida diferente (MOLETTA, 2000).

Tudo isso desperta interesse nas pessoas que vivem nos centros urbanos e que estão dispostas a gastar seu tempo e dinheiro desfrutando do lazer no meio rural. Porém, para que o visitante fique satisfeito, é necessário ter equipamentos e serviços adequados para que o turista seja bem atendido. É importante ainda que exista a preservação do meio ambiente, já que é incontestável que existe uma relação entre o turismo e o meio ambiente, visto que muitas vezes o meio ambiente se constitui na matéria-prima da atividade turística (MOLETTA, 2000).

Quando devidamente planejado, o turismo rural pode gerar vários benefícios à propriedade, aos proprietários e à comunidade, tais como: diversificação de renda; geração de empregos; preservação do patrimônio natural e cultural; melhoria na qualidade de vida local por meio de melhorias na infraestrutura básica (água, luz, estradas); diversificação dos polos turísticos por meio da descentralização do fluxo turístico nos destinos já 
consagrados; melhoria na formação educacional do homem do campo por meio da aquisição de novos conhecimentos; e desenvolvimento do espírito de participação e parceria ao trabalhar em conjunto com demais parceiros (MOLETTA, 2000).

Além disso, o turismo rural por vezes faz ressurgir as artes, as crenças, os cerimoniais, a linguagem e o patrimônio arquitetônico, que normalmente são restituídos ao cotidiano, mas que, a partir do implemento da atividade turística, são transformados em atrativos típicos usados como marcas locais interessantes para 0 turismo (PROGRAMA NACIONAL DE TURISMO RURAL NA AGRICULTURA FAMILIAR, 2004). No Programa, salienta-se ainda que o turismo rural na agricultura familiar visa o uso racional de recursos naturais, sua preservação, conservação e recuperação, beneficiando o meio ambiente.

O turismo rural pode também desencadear uma série de benefícios para a comunidade receptora, o chamado efeito multiplicador da atividade, pois um gasto turístico se propaga pela economia local e regional, ao gerar outras despesas sem as quais o turista não teria sido atendido. Assim, a atividade turística estimula uma série de atividades produtivas, como por exemplo, o artesanato, seja na própria propriedade ou em propriedades vizinhas.

De acordo com Philippi Jr e Ruschmann (2010), o turismo pode contribuir para o aumento da consciência ambiental e na educação para o consumo sustentável através da sua vasta rede de distribuição de serviços ou por meio de atividades realizadas de acordo com o que se entende por ecologicamente correto.

No entanto, o turismo também exerce impactos negativos sobre o ambiente. Conforme Philippi Jr e Ruschmann (2010), a atividade turística é grande consumidora de combustíveis, eletricidade, alimentos e água, além de gerar grandes quantidades de lixo e emissões poluentes.

Os impactos negativos podem ocorrer sobre o ambiente natural e seus componentes básicos (ar, água, vegetação, vida selvagem) bem como sobre o ambiente construído pelo homem (monumentos, sítios arqueológicos) e podem ser causados pelas atividades e comportamentos do turista ou decorrente da implantação da infraestrutura para servir o turismo (PHILIPPI JR; RUSCHMANN, 2010).

Muitos atrativos foram destruídos ou degradados violentamente devido a atividade turística massiva. Nesse sentido foram criadas algumas leis e normas que visam proteger a cultura $e$ as características das comunidades receptoras, as paisagens e os habitats e a economia rural, incentivar o crescimento a longo prazo da atividade turística, que estimulará a qualidade da experiência buscada pelos visitantes e a compreensão, liderança e visão também a longo prazo dos empreendedores (PHILIPPI JR; RUSCHMANN, 2010).

\section{Multifuncionalidade do meio rural e agricultura familiar}

Cristóvão (2002), atualmente o desenvolvimento do meio rural está muito ligado a diversificação da sua economia. A ideia de diversificação da economia rural decorre, cada vez mais, do reconhecimento de que o espaço rural é bem mais do que apenas um fornecedor de matérias primas, mas sim um espaço multifuncional (CRISTÓVÃO, 2002). Assim, o autor explica que o meio rural possui uma nova legitimidade, fundada na representação do campo como símbolo de liberdade, paisagem, beleza e saúde e que tem provocado o aparecimento de novas procuras e comporta potencialidades que podem ser aproveitadas a favor do meio rural, levando em consideração também os riscos.

Conforme Cristóvão (2002), assumir o meio rural como espaço multifuncional implica em uma lógica de identificação e valorização de recursos existentes, do seu potencial endógeno. E neste quadro, as expectativas de revitalização socioeconômica das áreas rurais apontam para estratégias de promoção e valorização de recursos (antigos, atuais e novos produtos agrícolas e agroindustriais, paisagem, fauna, flora, patrimônio histórico, tradições culturais, festas, música, entre 
outros) fomentando novas oportunidades de negócio e de criação de emprego, potencializando a retenção de mais valia e a distribuição de riqueza, aspectos vitais para fixar a população e dar vida aos territórios.

De acordo com Fucks (2005), a partir da década de 90, os espaços rurais dos países americanos vêm passando por importantes transformações, que interferem tanto na agricultura como no meio rural.

Essas mudanças são percebidas pela inserção de novas funções e pela diversificação das suas atividades produtivas. Elas têm sido motivadas pela inserção de uma gama de atividades, de natureza agrícola e não agrícola, definidas pelas novas demandas da sociedade contemporânea.

Segundo Klein, Elesbão e Souza (2015), as transformações ocorridas no espaço rural contribuíram para a constituição de uma nova realidade, um novo rural, caracterizado por uma diversidade de ocupações, serviços e funções. Assim, o espaço rural passa a ser visto não mais como lugar sem perspectiva, e sim como um espaço dinâmico e diversificado, com muitas potencialidades.

Os autores explicam também que o meio rural brasileiro é extremamente heterogêneo e de uma diversidade sociocultural muito grande e assim, a agricultura familiar se destaca na medida em que é vista como potencialmente mais capaz de desempenhar funções estratégicas econômicas, produtivas, ambientais e sociais, diferentemente da agricultura patronal.

Conforme Veiga (1998), nos últimos anos evoluiu muito a percepção sobre as vantagens que podem trazer as políticas públicas de fortalecimento e principalmente expansão da agricultura familiar, isso porque, com muito atraso, as elites brasileiras começam a identificar os agricultores familiares como um grupo social diferente e reconhecer como um dos agentes coletivos do processo de desenvolvimento rural e talvez por isso, não seja exagerado o otimismo em esperar que este grupo social venha a ser visto como o segmento importante da estratégia de desenvolvimento que o Brasil precisa.
Compreende-se, a partir disso, que a agricultura familiar é aquela em que a família, ao mesmo tempo que é proprietária, assume os trabalhos no estabelecimento produtivo (TEDESCO, 1999).

Adrioli (2009, p.13), explica que a "agricultura familiar é constituída por famílias de agricultores que com o seu próprio trabalho produzem alimentos." Conforme o autor, duas características merecem importância. Uma que aponta que na agricultura familiar é o trabalho da própria família que é responsável pela geração de renda, diferente da agricultura patronal, onde é aplicada mão de obra assalariada. E outra, que indica que a agricultura familiar é responsável pela maior parte da produção de alimentos, principalmente por sua característica de integrar a produção e o consumo.

Então, pensar a agricultura familiar na lógica da organização de processos produtivos permite constituir alternativas econômicas para a permanência das famílias no meio rural, promovendo a inclusão social e criando oportunidades para a geração de renda.

Segundo Conti, Pies e Cecconello (2006), o fortalecimento da agricultura familiar deve se dar a partir do controle e da organização da produção já que é um elemento importante para o enfrentamento do modelo dominante que dificulta e exclui a inserção mais favorável da produção familiar no mercado e na conquista de políticas públicas que possam ampliar a capacidade de competitividade e as oportunidades de crescimento econômico dos segmentos familiares.

Diante disso é necessário o fortalecimento das organizações econômicas da agricultura familiar, para que elas tenham condições de enfrentar a perversidade das regras do mercado liberal e organizar a comercialização dos produtos utilizando regras solidárias e de cooperação entre os produtores e consumidores. É necessário o empoderamento do cooperativismo e das inúmeras formas de associativismo, para que haja a diminuição dos custos do sistema produtivo (CONTI; PIES; CECCONELLO, 2006). 
Conti, Pies e Cecconello (2006) ressaltam também que a agricultura familiar é, para muitos trabalhadores, a principal atividade de trabalho, renda, alimentos e dignidade. No Brasil, este tipo de agricultura é responsável por mais de $40 \%$ do valor bruto da produção agropecuária e correspondem a $10,1 \%$ de todo o PIB (Produto Interno Bruto) do país. Reúne 4,2 milhões de estabelecimentos em todo - Brasil e representa $84 \%$ dos estabelecimentos rurais. Emprega $70 \%$ da mão de obra do campo e produz grande parte dos alimentos que vão à mesa dos brasileiros (CONTI; PIES; CECCONELLO, 2006).

Nesse contexto, Klein, Elesbão e Souza (2015), destacam o turismo rural, uma atividade que pode representar uma importante estratégia de desenvolvimento, visto que pode favorecer a ativação de espaços rurais, conservação da natureza e criação de novos postos de trabalho.

Assim os autores entendem que a prática do turismo em acordo com a agricultura, contribui para a conservação do ambiente natural e cultural garantindo a manutenção do tecido social das comunidades.

\section{Turismo rural na agricultura familiar $e$ as políticas públicas relacionadas}

Atualmente os espaços rurais vêm passando por importantes transformações, que interferem tanto na agricultura como no meio rural. Conforme Fucks (2005), elas têm sido motivadas pela inserção de uma gama de atividades, de natureza agrícola e não agrícola, definidas pelas novas demandas da sociedade contemporânea.

As variadas estratégias visam buscar uma menor dependência em relação aos insumos e ao crédito e viabilizando uma estrutura mais estável, onde possam comercializar os seus produtos. A leitura dessa nova ruralidade, mostra várias possibilidades de desenvolvimento no espaço rural, o que pode ser percebido a partir, sobretudo, do turismo. Assim, o fenômeno turístico vai assumindo feições próprias de acordo com as regiões onde se desenvolve e maior expressão devido à mídia e ao contexto econômico e sociocultural que condicionou a sua manifestação e disseminação no meio rural (FUCKS, 2005).

As áreas rurais que eram entendidas apenas como um local de trabalho relacionado a atividades agropecuárias passam a incorporar diversos aspectos relacionados com o lazer e o ludismo. Deste modo, mediante inserção de equipamentos turísticos e prestação de serviços de hospedagem, alimentação e atividades recreativas, adequação da infraestrutura e instalações da propriedade e a qualificação dos recursos humanos, o turismo pode trazer benefícios, tanto para as famílias rurais como para as urbanas (FUCKS, 2005).

No Brasil, o segmento de turismo rural é reconhecido oficialmente pelo Ministério do Turismo. O Turismo Rural na Agricultura Familiar (TRAF) e o agroturismo são variações reconhecidas oficialmente pelo ministério e caracterizadas pelo maior contato dos turistas com as práticas de trabalho nas propriedades rurais. Porém, o TRAF diferencia-se por incluir no contexto do turismo a agricultura familiar (ARAÚJO; BAHIA; FERREIRA, 2011).

Segundo Brasil, citado por Araújo, Bahia e Ferreira (2011), a inclusão do TRAF como estratégia do Ministério do Desenvolvimento Agrário para criar novas alternativas de renda aos agricultores familiares demonstra que a área vem sendo contemplada pelas políticas públicas dos dois ministérios.

Conforme o Programa Nacional de Turismo Rural na Agricultura Familiar (2004), o que pretendem - Ministério do Desenvolvimento Agrário e o Ministério do Turismo é trabalhar de forma integrada, utilizando da atividade turística no meio rural como fator de mobilização nacional para proporcionar retorno financeiro e melhores condições de vida aos produtores, famílias e comunidades rurais.

O conceito oficial, elaborado em 2004, de acordo com o Programa Nacional de Turismo na Agricultura Familiar do Ministério do Desenvolvimento Agrário, define TRAF como

atividade turística que ocorre na unidade de produção dos agricultores familiares que 
mantêm as atividades econômicas típicas da agricultura familiar, dispostos a valorizar, respeitar e compartilhar seu modo de vida, o patrimônio cultural e natural, ofertando produtos e serviços de qualidade e proporcionando bem estar aos envolvidos.

Este conceito, entre outras funções, baliza políticas públicas e orienta a inserção dos empreendedores à programas relacionados a esta área.

Entretanto sabe-se que as iniciativas públicas e privadas tem se mostrado insuficientes no que diz respeito a promover e fomentar o desenvolvimento do turismo rural, principalmente pela falta de créditos, regulamentações, incentivos e outras informações que orientem os produtores rurais, os investidores e 0 próprio governo (ARAÚJO; BAHIA; FERREIRA, 2011).

As políticas públicas mais conhecidas nesta área são o Programa Nacional de Turismo Rural na Agricultura Familiar (PNTRAF) e Programa Nacional de Fortalecimento da Agricultura Familiar (PRONAF).

De acordo com Bonetti (2012), o Programa Nacional de Turismo Rural na Agricultura Familiar foi instituído em 2004 e surgiu a partir de uma iniciativa do Ministério do Desenvolvimento Agrário, porém com forte participação do Ministério do Turismo. O objetivo do programa conforme o autor, é promover o desenvolvimento rural sustentável por meio da implantação e fortalecimento das atividades turísticas integradas aos arranjos produtivos locais, resultando na agregação de renda e geração de postos de trabalho no meio rural e consequente melhoria nas condições de vida dos agricultores familiares (PROGRAMA NACIONAL DE TURISMO RURAL NA AGRICULTURA FAMILIAR, 2004).

Já o Programa Nacional de Fortalecimento da Agricultura Familiar, conforme Mior (2005, p. 164), é um programa que tem como objetivo geral proporcionar condições para o aumento da capacidade produtiva, para a geração de empregos e para o incremento da renda, contribuindo para a melhoria da qualidade de vida e a ampliação do exercício da cidadania por parte dos agricultores familiares e por objetivos específicos ajustar as políticas públicas a realidade da agricultura familiar, viabilizar a infraestrutura rural necessária para a melhoria do desempenho produtivo e da qualidade de vida da população rural, fortalecer os serviços de apoio ao desenvolvimento da agricultura familiar, elevar o nível de profissionalização de agricultores familiares, proporcionando a eles novos padrões tecnológicos e de gestão; e favorecer o acesso de agricultores familiares e suas organizações aos mercados de produtos e insumos.

Assim, é perceptível que existe um esforço por parte do governo em pensar políticas públicas relacionadas ao turismo e a agricultura familiar, no entanto, é necessário analisar se estas políticas estão de fato sendo implementadas, o que, de certa forma, foi analisado no estudo de caso apresentado a seguir.

\section{0 caso do Sítio 7 Águas em Santa Cruz do Sul - RS}

O município de Santa Cruz do Sul se localiza no centro do Estado do Rio Grande do Sul. Sua economia é baseada principalmente na produção e exportação de tabaco, e por isso, na maior parte das propriedades a agricultura é trabalhada de forma familiar.

Neste trabalho estudamos uma propriedade específica que os proprietários, além de manter atividades agropecuárias passaram a trabalhar o turismo rural. O Sítio 7 Águas, como é denominada, se localiza no interior do município de Santa Cruz do Sul, mais especificamente na localidade de Linha Boa Vista e oferece uma ampla área de camping, casas de lazer, restaurante e piscinas além de passeios de trator e o acompanhamento das lidas do campo, se configurando como um empreendimento de turismo rural.

Para analisar o repasse dos subsídios por parte das entidades ligadas à área rural, além de entrevistar os proprietários do empreendimento citado, foi realizada uma pesquisa com gestores da EMATER/ASCAR - Empresa Brasileira de Extensão Rural / Associação Sulina de Crédito e Assistência Rural de Santa Cruz do Sul e com o SENAR Serviço Nacional de Aprendizagem Rural da região 
do Vale do Rio Pardo - região em que o município e a propriedade estão inseridos - pois elas se configuram como as principais apoiadoras da diversificação de atividades no meio rural da região.

Como resultado, foi possível perceber que tanto as entidades como o empreendimento de turismo rural Sítio 7 Águas vêem o turismo como uma forma de diversificação e principalmente como geradora de renda e por este motivo, as entidades procuram dar apoio aos produtores que pretendem investir na área do turismo rural.

Como subsídio, o Senar possibilita os cursos de capacitação na área do turismo e a Emater/Ascar possibilita a extensão rural, oportunizando ao agricultor familiar o acesso as políticas públicas, instruções sobre a qualidade dos produtos vendidos, recuperação de áreas degradadas, entre outros.

No entanto, com a análise das entrevistas, foi possível perceber que a família proprietária do Sítio 7 Águas não recebeu nenhum tipo de auxílio das entidades, só da prefeitura e da Secretaria de Turismo do município, o que faz entender que não houve nenhuma iniciativa por parte das entidades como também não houve busca de auxílio por parte da família.

Porém, ao iniciar as atividades em um novo empreendimento, independente da área de atuação, é importante procurar entidades e órgãos que trabalhem, discutam e apoiem a atividade. Além dos subsídios que podem ser oferecidos, esse contato é importante, pois possibilita a formação de parcerias com estas instituições, o que permite a atualização constante sobre assuntos relacionados a atividade. Além disso, o contato com pessoas especializadas na área e que tem uma visão mais ampla de mercado, pode contribuir para tirar dúvidas e sugerir mudanças e inovações no trabalho e na propriedade.

As entidades também são importantes para ajudar a fazer o planejamento das atividades a serem desenvolvidas no empreendimento para que o mesmo seja capaz de receber turistas e trabalhar com o turismo de forma adequada. Entre as atividades oferecidas pelas entidades pesquisadas estão os cursos de capacitação desenvolvidas pelo
Senar e o trabalho em grupo, desenvolvido por meio das rotas e roteiros, trabalhado pela Emater/Ascar. De tempos em tempos, também são promovidas pelas entidades, atividades como palestras, seminários e encontros onde normalmente algum representante do Sítio 7 Águas procura participar para que possa se atualizar e trocar ideias. $O$ empreendimento também faz parte da ATURVARP, Associação de Turismo da Região do Vale do Rio Pardo, porém apenas como forma de ter seu estabelecimento divulgado.

Com relação à divulgação das atividades, propostas pelas entidades, normalmente esta se faz em locais como Sindicatos de Trabalhadores Rurais ou em eventos que tenham relação com as pessoas e empresas do meio rural para que o produtor, interessado na atividade, possa tomar conhecimento e participar. Entretanto, a Emater/Ascar raramente é procurada para realizar atividades no segmento do turismo e o Senar, só inicia os cursos de formação na área se tiver um mínimo de demanda interessada, caso contrário ele não é desenvolvido, o que muitas vezes se torna um empecilho para os interessados, já que para conseguirem a capacitação eles precisam formar um grupo, o que nem sempre é fácil.

Infelizmente, como percebido a partir da pesquisa, poucos agricultores familiares buscam auxílio das entidades para trabalhar com o turismo, como visto a partir do empreendimento analisado, que também não o fez. Porém, durante o início dos trabalhos no ramo, os proprietários do empreendimento tiveram várias dúvidas, entre elas a mais instigante: o investimento vale a pena? Vai dar retorno? Essas dúvidas talvez pudessem ser esclarecidas com a ajuda das entidades que, por estarem constantemente em contato com o assunto, poderiam verificar a possibilidade de 0 empreendimento de se tornar rentável ou não. Porém, como não houve contato, por falta de iniciativa de ambas as partes, a dúvida ficou até que o empreendimento foi aberto à visitação.

Além dos subsídios oportunizados pelas entidades, elas também incentivam o agricultor a procurar o auxílio do poder público municipal e a fazer 
uso das políticas públicas, como PRONAF, que é utilizado pelo Sítio 7 Águas para investir em melhorias no empreendimento.

A partir do breve relato do estudo realizado com o empreendimento de Santa Cruz do Sul e com as entidades Emater/Ascar e Senar, é possível perceber que no município o turismo ainda é incipiente e por muitas vezes encarado com pouca relevância. Existem iniciativas por parte das entidades, que, no entanto, nem sempre saem do papel e falta de procura por parte dos empreendedores, o que acaba fazendo com que a atividade turística no meio rural não se consolide.

Com relação às políticas públicas, é perceptível que a única conhecida e utilizada pelo empreendimento analisado e também sugerida pelas entidades é o Programa Nacional de Fortalecimento da Agricultura Familiar (PRONAF), que na região é utilizado de forma bem ampla pelos agricultores familiares para investir no cultivo do tabaco.

Nesse sentido, é possível perceber que para que o turismo rural se configure de forma adequada e ganhe força dentro das propriedades que trabalham com a agricultura familiar na região é necessário, em primeiro lugar, que as famílias queiram, de fato, diversificar sua renda através da atividade turística e a partir disso que elas busquem as entidades para se capacitar e verificar a possibilidade de auxílios.

É importante também trabalhar em conjunto com os demais empreendedores da área, com pessoas que possuam os mesmo interesses e participar de associações do ramo para buscar condições e políticas públicas que sejam favoráveis ao desenvolvimento da atividade. Além de aumentar os horizontes, o trabalho em conjunto possibilita uma maior força de ação, o que muitas vezes falta, principalmente quando não se tem capacitação suficiente.

Cabe desatacar também que pensar o turismo rural na agricultura familiar de forma regionalizada e horizontal, pode contribuir para o desenvolvimento do mesmo, uma vez que juntos, os agricultores se fortificam e conseguem com maior facilidade alcançar políticas públicas, encarar mais firmemente o lado perverso da globalização e assim configurar a região como um novo destino turístico a ser visitado.

\section{Considerações finais}

Atualmente, o meio rural ganhou uma visão mais ampla e engloba muito mais do que um simples espaço onde se desenvolvem atividades agropecuárias. Ele pode ser aproveitado de vários outros modos, uma vez que vem se configurando como um espaço multidisciplinar.

A atividade turística é uma destas formas. Ela se utiliza do meio rural para proporcionar descanso, fuga da rotina das pessoas que se sentem sufocadas pela correria dos grandes centros.

Assim, o turismo rural é visto como uma boa alternativa para os empreendedores que pretendem diversificar sua renda como também pelos visitantes que podem satisfazer suas necessidades de entrar em contato com a natureza, descansar, conhecer costumes e tradições típicas de cada local.

A partir do que foi visto, percebe-se que o Brasil ainda é muito carente com relação a políticas públicas voltadas ao desenvolvimento do turismo rural. Existem algumas iniciativas como o Programa Nacional de Turismo Rural na Agricultura Familiar (PNTRAF) e Programa Nacional de Fortalecimento da Agricultura Familiar (PRONAF), no entanto, como no caso estudado, o PRONAF é o único utilizado pela família empreendedora e também o único indicado pelas entidades.

Verifica-se assim a necessidade de trabalhar em grupos, para, de alguma forma, tentar suprir esta falta de estímulos provenientes das políticas públicas, pois esta pode ser uma das formas de conseguir desenvolver o turismo rural na agricultura familiar de municípios como o que foi estudado. Além disso, é importante ressaltar, que a assistência das entidades é importante para o desenvolvimento da atividade turística na agricultura familiar, então buscar estas entidades, conhecê-las, participar de suas atividades e firmar parcerias é de fundamental importância para 
ingressar na caminhada rumo a implantação do turismo rural na agricultura familiar.

Por fim, é importante colocar que a região do Vale do Rio Pardo e o município de Santa Cruz do Sul, em específico, é muito influenciada pelas forças das multinacionais do tabaco, maior força verticalizadora da região, o que trava iniciativas de diversificação da renda na área rural e muitas vezes impede 0 desenvolvimento rural no município. Entretanto, ainda assim o turismo rural pode ser rentável e dar certo, assim como ocorre no Sítio 7 Águas, que possui uma demanda relativamente grande de turistas para as casas de lazer, principalmente na alta temporada, mas também fora dela.

\section{Referências}

ADRIOLI, Antônio Inácio. Tecnologia e agricultura familiar: uma relação de educação. ljuí: Ed. Unijuí, 2009.

ALMEIDA, Joaquim Anécio. RIEDL, Mário (coord.). Anais do II Congresso Internacional de Turismo Rural e Desenvolvimento Sustentável. Santa Maria: Ed. Da UFSM, 2000.

ARAÚJO, A. L. M.; BAHIA, E. T.; FERREIRA, W.R. Turismo rural na agricultura familiar: um estudo sobre as possibilidades e limitações no município de Alfredo Vasconcelos, MG. Rio de Janeiro, 2011. Disponível em <http://www.ivt.coppe.ufrj.

br/caderno/index.php?journal=caderno\&page=art icle\&op=view\&path \%5B\%5D=598\&path\%5B\%5 $\mathrm{D}=304>$ Acesso em: 3 set. 2014.

BONETTI, Lucas A. Políticas públicas federais de turismo rural e o turismo rural na agricultura familiar (TRAF). Uberlândia, 2012. Disponível em<http://www.lagea.ig.ufu

.br/xx1enga/anais_enga_2012/eixos/1230_1.pdf. > Acesso em: 05 out. 2014.

CONTI, Irio Luiz; PIES, Marcelino; CECCONELLO, Rene. Agricultura familiar: caminhos e transições. Passo Fundo: IFIBE, 2006.

CRISTÓVÃO, Artur. Mundo rural: entre as representações (dos urbanos) e os benefícios reais (para os rurais). In: RIEDL, Mário; ALMEIDA, Joaquim Anécio; VIANA, Andyara Lima Barbosa (Org). Turismo rural: tendências e sustentabilidade. Santa Cruz do Sul: EDUNISC, 2002.
KLEIN, Angela Luciane; ELESBÃO, Ivo; SOUZA, Marcelino de. O turismo rural pedagógico no contexto da multifuncionalidade da agricultura. In: Desafios da gestão: interfaces do turismo, agronegócio e meio ambiente. JúNIOR, David Lorenzi (et. al). Santa Maria: Cesma, 2015.

FUCKS, Patrícia Marasca. Turismo, agricultura e patrimônio: São Lourenço do Sul (RS). Santa Maria: FACOS, 2005.

MINISTÉRIO DO TURISMO. Disponível em <http://www.turismo.gov.br/turismo/ programas_acoes/regionalizacao_turismo/estrut uracao_segmentos/rural.html> Acesso em: 28 ago. 2014.

MIOR, Luiz Carlos. Agricultores familiares, agroindústrias e redes de desenvolvimento rural. Chapecó: Argos, 2005.

MOLETTA, Vania Florentino. Turismo Rural. 2.ed. Porto Alegre: SEBRAE/RS Editora, 2000.

PANORAMA EMPRESARIAL DE TURISMO RURAL ,2010. Guia PETR: Panorama Empresarial de Turismo Rural 2010. Coordenação Geral IDESTUR - Andreia Roque. São Paulo, 2010. Disponível em <http://www.idestur.org.br/download/2012021911 2 607.pdf> Acesso em: 26 out 2016

PHILIPPI JUNIOR, Arlindo; RUSCHMANN, Doris Van de Meene (coord.). Gestão ambiental e sustentabilidade no turismo. 1.ed. Barueri: Manole, 2010.

PROGRAMA NACIONAL DE TURISMO RURAL NA AGIRCULTURA FAMILIAR, 2004. Disponível em $<$ file:///C:/Users/Acer/Downloads/Programa_Naci onal_de_Turismo_na_Agricultura_Familiar\%20(4 ).pdf> Acesso em 27 out 2016.

RUSCHMANN, Doris Van de Meene. Turismo e planejamento sustentável: a proteção do meio ambiente. Campinas: Papyrus, 1997.

SANTOS, Eurico de Oliveira. Agroturismo e turismo rural: alternativa econômica para a metade sul do Estado do Rio Grande do Sul. Santa Maria: FACOS, 2005.

TEDESCO, João Carlos (org.). Agricultura familiar: realidades e perspectivas. Passo Fundo: EDIUPF, 1999.

VEIGA, José Eli da. Diretrizes para uma nova política agrária. In: Reforma agrária e desenvolvimento sustentável, NEAD, Ministério do Desenvolvimento Agrário, Brasília, 2000, p. 1936. 